\title{
The relationship between living alone and depressive symptoms among older gay men: the moderating role of sense of belonging with gay friends
}

\author{
Suzanne McLaren \\ School of Health Sciences and Psychology, Federation University Australia, Australia
}

ABSTRACT

Background: Living alone is a risk factor for depressive symptoms among older adults, although it is unclear if it is a risk factor for older gay men. A sense of belonging to the gay community is protective and might compensate for living alone. This research investigated whether a sense of belonging with gay friends weakened the relationship between living alone and depressive symptoms among older gay men.

Methods: A community sample of 160 Australian gay men aged 65-92 years completed the Center for Epidemiologic Studies Depression Scale and two visual analogue scales assessing a sense of belonging with gay friends.

Results: Results supported the moderation model, with increasing levels of belonging with gay friends weakening the relationship between living alone and depressive symptoms.

Conclusion: Results imply that enhancing a sense of belonging with gay friends among older gay men who live alone is likely to be a protective factor in relation to depressive symptoms.

Key words: living alone, depressive symptoms, gay men, sense of belonging

Older age (Pirkis et al., 2009; Zhang et al., 2012) and sexual orientation (Cochran and Mays, 2009) are risk factors for depression among men. Pirkis et al. (2009) reported the age-adjusted prevalence rate of clinically significant depression to be $8.6 \%$ and a major depressive episode to be $1.9 \%$ among a community sample of 9,013 Australian men aged 60 years and over. In relation to sexual orientation, Cochran and Mays (2009) reported that $21.5 \%$ of their sample of gay men were likely to meet the criteria for major depressive disorder in the previous 12 months and were 2.3 times more likely to have a probable diagnosis than heterosexual men. It is difficult to obtain prevalence rates specifically for older gay men. Available evidence indicates that $30 \%$ of a sample of gay men aged 50-82 years self-reported feeling depressed (Shippy et al., 2004) and that the average score for depressive symptoms among a sample of

Correspondence should be addressed to: Suzanne McLaren, School of Health Sciences and Psychology, Federation University Australia, PO Box 663, Ballarat, VIC, 3353, Australia. Phone: +61 3 53279628. Email: s.mclaren@federation.edu.au. Received 11 May 2016; revision requested 20 Jun 2016; revised version received 22 Jun 2016; accepted 8 Jul 2016. First published online 9 August 2016. gay men aged 44-75 years demonstrated that the sample experienced depressive symptoms "some or a little of the time" (Wight et al., 2012). Given that older gay men are exposed to the risks associated with age and sexual orientation, it is likely to be a significant problem for this population.

A risk factor for depression among older adults is living alone (Chou et al., 2006; Tintle et al., 2011; Oh et al., 2015). This relationship has been explained at least in part by a lack of belonging. Living alone has been identified as a risk factor for thwarted belongingness, which occurs when the basic human need to belong is unmet (Van Orden et al., 2010). Baumeister and Leary (1995) proposed that people "have a pervasive drive to form and maintain...lasting, positive, and significant interpersonal relationships" (p. 1). These interpersonal relationships need to be frequent, positive, and stable (Baumeister and Leary, 1995). Others have proposed that people need a psychological sense of belonging for mental health (Hagerty et al., 1992). Hagerty et al. (1992) defined a sense of belonging as an individual's experience of being valued or important, and as though one fits in with those around them. 
Low levels of a sense of belonging have been associated with depressive symptoms among older adults (McLaren et al., 2007) and among gay men (McLaren et al., 2008). The relationship has not been investigated among older gay men.

Although there is a theoretical explanation to link living alone with depression among older adults, empirical evidence is mixed, with the results varying according to gender, age, and nationality of the participants. For example, Oh et al. (2015) supported the relationship between living alone and higher levels of depressive symptoms among older men and women in a Korean sample aged 60 years and older. Tintle et al. (2011) found the relationship among a sample of Ukrainian older men but not older women (aged 50 years and older) and Chou et al. (2006) found the link in older women but not older men in their sample of Chinese adults aged 60 years and older. There appears to be just one study that has examined the link between living alone and depression among gay men. An Australian study of gay men aged 50 years and older (Lyons, 2015) did not find an association between living alone and depression, raising the possibility that the relationship is not evident among older gay men.

The mixed empirical evidence on the link between living alone and depression suggests that the relationship is likely to be more complex than a simple direct relationship. Purcell et al. (2012) conducted a study with 130 adults aged 50 years and older who suffered from a mood disorder and found that living alone was not associated with suicidal ideation. Results indicated, however, an interaction between living arrangements and family connectedness. Specifically, they found that older adults living with others and having higher levels of family connectedness reported significantly lower levels of suicidal ideation than those living alone. Whether family connectedness weakens the relationship between living alone and suicidal ideation was not detailed by the authors. It is likely, however, that relationships that assist to meet belongingness needs weaken the relationship between living alone and suicidal ideation. Given the strong relationship between depression and suicide (Nock et al., 2008), it is probable that this moderation effect would be evident for the living arrangements-depressive symptoms relation.

Further examining the possible relationship among living alone and depression among older gay men is important, given that as gay men age, they are more likely to live alone (Lyons et al., 2012). Lyons et al. (2012) found that $30 \%$ of gay men aged 40-49 lived alone, 38\% aged 50-59 lived alone, and $44 \%$ of gay men aged 60 and older lived alone. Other research has indicated that $65.8 \%$ of gay men aged 50-82 years lived alone (Shippy et al., $2004)$. In addition, older gay men $(40.66 \%)$ are more likely to live alone than older heterosexual men (15.15\%; Fredriksen-Goldsen et al., 2013). Several factors contribute to the high proportion of older gay men living alone. In countries such as Australia, gay men cannot marry, and although they can be "partnered," older gay men are less likely to have a partner than older heterosexual men (Stonewall, 2011; Fredriksen-Goldsen et al., 2013). In addition, older gay men are less likely to have children ( $28 \%$ compared with $88 \%$ of older heterosexual men) and to see their biological family on a regular basis (Stonewall, 2011). Consequently, older gay men are less likely than older heterosexual men to have a spouse/partner, children, or other family members to live with as they age.

The high proportion of older gay men living alone highlights the importance of further investigating the link between living alone and depressive symptoms among this sample, and in particular, whether thwarted belongingness associated with living alone can be compensated by belonging in other contexts. Research has demonstrated that belonging to the gay community can be a protective factor for gay men (McLaren et al., 2008; McLaren et al., 2013). Research indicates that one way gay and bisexual men experience gay community is through their relationships with their gay friends, both individually and as a network of friends (Woolwine, 2000; LeBeau and Jellison, 2009). Indeed, $63.5 \%$ of LeBeau and Jellison's sample reported that social life was a key advantage of being involved in the gay community. The men reported that romantic relationships and friendships were key reasons to be connected with the gay community. Gay friends provide a space for trust, shared interests, acceptance, mutual understanding, and emotional closeness (de Vries and Megathlin, 2009) and can perform many family functions (Woolwine, 2000; de Vries and Megathlin, 2009). Woolwine proposed that the friendships established between gay men are likely to be protective. Recent research confirmed this, indicating that belonging with gay friends was directly related to lower levels of depressive symptoms among a sample of gay men aged from 18 to 79 years (Morris et al., 2015). Whether belonging with gay friends can negate the thwarted belongingness associated with living alone among older gay men is unknown.

The proposal that belonging with gay friends can weaken the relationship between living alone and depressive symptoms is consistent with the riskprotective model of resiliency (Hollister-Wagner et al., 2001). The model proposes that the strength of the relationship between a risk factor 
Table 1. Frequency of demographic characteristics in sample $(N=164)$

\begin{tabular}{|c|c|c|}
\hline VARIABLE & $N$ & $\%$ \\
\hline \multicolumn{3}{|l|}{ Living arrangement } \\
\hline Live alone & 78 & 48.75 \\
\hline Live with another & 82 & 51.25 \\
\hline \multicolumn{3}{|l|}{ Relationship status } \\
\hline Partnered & 90 & 56.25 \\
\hline Unpartnered & 70 & 43.75 \\
\hline \multicolumn{3}{|l|}{ Highest level of education } \\
\hline Secondary school/trade certificate & 74 & 46.25 \\
\hline University degree & 86 & 53.75 \\
\hline \multicolumn{3}{|l|}{ Disclosure } \\
\hline$<25 \%$ & 18 & 11.25 \\
\hline $25 \%$ to $50 \%$ & 18 & 11.25 \\
\hline $51-75 \%$ & 28 & 17.50 \\
\hline$>75 \%$ & 96 & 60.00 \\
\hline
\end{tabular}

(living alone) and an outcome factor (depressive symptoms) depends upon the presence of protective factors (belonging with gay friends), with the protective factors weakening the relationship between risk and outcome.

In summary, living alone has been identified as a risk factor for depression in some samples of older adults. It has been theorized that this relationship can be explained, at least in part, by belongingness needs being unmet. It is unclear, however, whether living alone is related to depression among older gay men. It is also unclear whether belongingness needs being met through other mechanisms, such as gay friends, can compensate for thwarted belongingness associated with living alone and weaken the relationship between living alone and depressive symptoms among older gay men. The aim of the current study was, therefore, to investigate whether living alone is associated with depressive symptoms among older gay men, and whether belonging with gay friends moderates the relation between living alone and depressive symptoms among older gay men.

\section{Methods}

\section{Participants}

A convenience sample of 160 Australian selfidentified gay men aged from 65 to 92 years $(M=$ $72.74, S D=7.99)$ participated in the study. The participants lived in the state of Victoria, Australia. Details of the sample can be seen in Table 1. The majority of men were partnered, lived with another person, had completed a university degree, and had disclosed their sexual orientation to the majority of people they knew.

\section{Measures}

Potential participants were invited to participate in the study through an information letter that provided a brief written description of the research and the contact details for the researcher and relevant resources that could be accessed by the participant if they experienced any distress during or after completing the questionnaire, including a free 24-h telephone counseling service for gay men.

The demographic section of the questionnaire sought participants' details including their age, relationship status, living arrangements, highest education level achieved, and the degree of disclosure of their sexual orientation. The men indicated their sexual orientation by choosing from a number of options, including heterosexual, gay male, bisexual, and do not know/unsure. Only men who identified as gay were included in the study.

The 20-item Centre for Epidemiologic StudiesDepression Scale (CES-D) was used to measure depressive symptomatology (Radloff, 1977). Participants used a 4-point scale $(0=$ less than one day; $3=5-7$ days) to indicate how often they had experienced depressive symptoms over the past week (e.g. I felt that everything I did was an effort). The scale has a range of $0-60$, with higher scores indicating more depressive symptoms. A cutoff score of 12 has been demonstrated to have maximum sensitivity and specificity for identifying depression among older adults (Lewinsohn et al., 1997). The CES-D has shown strong internal consistency for a sample of gay men (Cronbach's $\propto=0.92$, Morris et al., 2015) and for the current sample (Cronbach's $\alpha=0.96$ ).

A sense of belonging with gay friends was assessed using two visual analogue scales (see Morris et al., 2015), which measured two psychological aspects of a sense of belonging (feeling needed or valued, and fit). Both visual analogue scales consisted of a 10-cm line anchored at each end with extreme positions ( 0 "Not needed or valued at all" to 10 "Completely needed or valued"; $0=$ Do not fit in at all to $10=$ Completely fit in"). Respondents placed a vertical line through both lines to indicate the extent to which they felt valued by and fitted in with their gay friends. The placement of the vertical line was measured to the nearest centimeter, and the two scores were summed. Total scores ranged between 0 and 20, with higher scores indicating a greater sense of belonging with gay friends. The measure showed high internal consistency for the current sample (Cronbach's $\propto=0.97$ ).

\section{Procedure}

Several strategies were used to recruit the sample. Older gay men were recruited at gay community 
Table 2. Mean scores and standard deviations of variables, and correlations between variables $(N=160)$

\begin{tabular}{|c|c|c|c|c|c|}
\hline VARIABLE & 1 & 2 & 3 & $M$ & $\mathrm{SD}$ \\
\hline 1. Depressive symptoms & - & $-0.43^{* * *}$ & $-0.34^{* * *}$ & 12.77 & 14.97 \\
\hline 2. Living arrangement $\mathrm{t}^{\mathrm{a}}$ & $-0.40^{* * *}$ & - & $0.24^{* *}$ & - & - \\
\hline 3. Belonging-gay friends & $-0.24^{* *}$ & $0.19^{*}$ & - & 13.82 & 5.54 \\
\hline
\end{tabular}

Note. Bivariate correlations are above the diagonal, and partial correlations, controlling for age, relationship status, education level, disclosure of sexual orientation, and type of questionnaire, are below the diagonal.

${ }^{\mathrm{a}} 1=$ living alone, $2=$ living with another.

${ }^{*} p<0.05 .{ }^{* *} p<0.01 .{ }^{* * *} p<0.001$

events and functions, where the research was promoted and paper copies of the questionnaire were distributed. The questionnaire was also available online, and a link was placed on websites and in newsletters aimed at older gay men. Advertisements were also placed in agencies (e.g. healthcare services) that were utilized by older gay men. Snowball sampling was also used.

The men completed either a paper-based ( $n$ $=76,47.5 \%)$ or online questionnaire $(n=84$, $52.5 \%$ ). A total of 150 paper questionnaires were distributed, resulting in a response rate of $50.7 \%$. Most men (91\%) who accessed the online survey completed it. The order of the measures was counterbalanced to minimize order effects.

\section{Data analysis}

Initially, descriptive statistics and correlations between the key variables were conducted. The moderation model was tested using Process (Model 1; Hayes, 2013) in SPSS. The number of bootstrap samples for bias corrected bootstrap confidence intervals (CIs) was 10,000, and a bootstrapped 95\% CI was used to infer significance. Significance is supported if the CI does not include zero. Given that the variables of age (Polku et al., 2015), relationship status, and education level (Kamiya et al., 2013) are related to depression among older adults, questionnaire type (online/paper) is related to a sense of belonging among gay men and lesbians (McLaren et al., 2013), and the disclosure of sexual orientation is related to suicide among gay men and lesbians (Plöderl et al., 2014); these variables were controlled for in the analyses.

\section{Results}

A total of $31.2 \%$ of the older gay men scored 12 or above on the CES-D, indicating that almost onethird of the sample reported clinically significant levels of depressive symptoms. The mean scores and standard deviations for each variable, and the

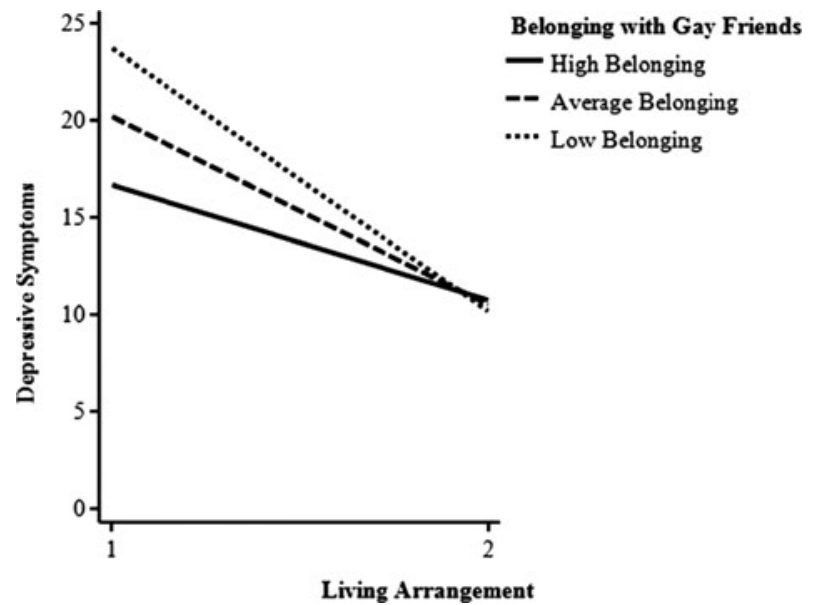

Figure 1. Interaction between living arrangement and belonging with gay friends predicting depressive symptoms. Note. Living Arrangement: 1 = living alone, 2 = living with another.

bivariate and partial correlations between variables, are shown in Table 2. Results of the correlations indicated that living alone was associated with lower levels of belonging with gay friends and higher levels of depressive symptoms. Higher levels of belonging with gay friends were associated with fewer depressive symptoms.

Results testing the moderation model can be seen in Table 3. The interaction term was significantly related to depressive symptoms, providing support for the moderation model. The interaction term explained an additional $1.3 \%$ of the variance in depressive symptoms, $F(1,151)=5.25, p=$ 0.023 . Figure 1 displays the interaction between living arrangement and belonging with gay friends predicting depressive symptoms. For the graph, the effects of living arrangement and belonging with gay friends on depressive symptoms were plotted at three points: high, average, and low. High, average, and low values for belonging with gay friends were $+1 \mathrm{SD}, 0 \mathrm{SD}$, and $-1 \mathrm{SD}$, respectively, of the centered mean of zero. The direct effect between living arrangement and depressive symptoms was significant for low, $b=-13.55, p<0.001(95 \%$ 
Table 3. Results of regression analysis testing moderation model $(N=164)$

\begin{tabular}{|c|c|c|c|}
\hline VARIABLE & B & SE & $95 \% \mathrm{CI}$ \\
\hline Constant & $-31.53^{*}$ & 14.11 & {$[-59.40,-3.66]$} \\
\hline Age & $1.10^{* * *}$ & 0.10 & {$[0.89,1.30]$} \\
\hline Relationship status $^{a}$ & -3.30 & 1.82 & {$[-6.90,0.30]$} \\
\hline Education level & 0.07 & 1.59 & {$[-3.08,3.22]$} \\
\hline Disclosure & -0.75 & 0.76 & {$[-2.25,0.76]$} \\
\hline Questionnaire type ${ }^{b}$ & 2.67 & 1.57 & {$[-0.44,5.78]$} \\
\hline Living arrangement $\mathrm{t}^{\mathrm{c}}$ & $-19.20^{* * *}$ & 4.75 & {$[-28.57,-9.82]$} \\
\hline Belonging-gay friends & $-1.32^{* *}$ & 0.45 & {$[-2.21,-0.42]$} \\
\hline Living arrangement $\times$ belonging & $0.68^{*}$ & 0.30 & {$[0.09,1.27]$} \\
\hline $\mathrm{R}^{2}$ & 0.61 & & \\
\hline $\mathrm{F}$ & $29.35^{* * *}$ & & \\
\hline
\end{tabular}

Note. ${ }^{\mathrm{a}} 1$ partnered, $2=$ unpartnered; ${ }^{\mathrm{b}} 1=$ paper, $2=$ online; ${ }^{\mathrm{c}} 1=$ living alone, $2=$ living with another.

${ }^{*} p<0.05 .{ }^{* *} p<0.01$. ${ }^{* *} p<0.001$.

$\mathrm{CI}=-18.80,-8.29$ ), average, $b=-9.76, p$ $<0.001$ (95\% CI $=-13.47,-6.05)$, and high, $b=-5.98, p=0.011(95 \%$ CI $=-10.59$, -1.37 ), levels of belonging with gay friends. Results indicate that the relationship between living alone and depressive symptoms weakened with increasing levels of belonging with gay friends.

\section{Discussion}

The aim of this study was to investigate the relationship between living alone, a sense of belonging with gay friends, and depressive symptoms among older gay men, and whether the living alonedepressive symptoms relationship was weakened by having a sense of belonging with gay friends. This study appears to be the first to demonstrate that living alone is associated with depressive symptoms among older gay men. Although not tested in this study, others have proposed that this relationship exists due to thwarted belongingness (Van Orden et al., 2010). Results of this study are inconsistent with the only other study that has investigated this relationship among older gay men (Lyons, 2015). Lyons (2015) did not demonstrate a significant relationship between living alone and depressive symptoms among a sample of gay men aged 50 years and older. The younger age of Lyons' sample may at least partly explain the different result. As gay men age, they are more likely to live alone (Lyons et al., 2012). In addition, it is possible that age moderates the living alonedepressive symptoms relationship such that older age strengthens the relationship. Future research could test this proposed moderation model.

This study appears to be the first to investigate whether a sense of belonging with gay friends moderates the relationship between living alone and depressive symptoms among older gay men. Results supported the moderation model. Increasing levels of a sense of belonging with gay friends weakened the relationship between living alone and depressive symptoms. This finding highlights the important role that belonging with gay friends can play in the mental health of older gay men who live alone. Consistent with the risk-protective model of resiliency (Hollister-Wagner et al., 2001), it is evident that the presence of the protective factor (i.e. high levels of belonging with gay friends) weakens the relationship between living alone and depressive symptoms among older gay men. The results suggest that if older gay men's belongingness needs are met through other mechanisms, the relationship between living alone and depressive symptoms is weakened.

It is important to note, however, that the relationship between living alone and depressive symptoms remained significant even for older gay men with high levels of belonging with gay friends. This suggests that the thwarted belongingness associated with living alone is not entirely compensated for by high levels of belonging with gay friends.

The results of this study reinforce the importance of a sense of belonging with gay friends for the mental health of older gay men, and particularly those who live alone. Assisting older gay men to develop close emotional bonds with other gay men is likely to be beneficial for their mental health. Lyons et al. (2013) note that programs that assist older gay men to come together to form friendships may be particularly valuable. Within Australia, the Men's Shed movement has been seen to fulfill a significant role in bringing men together. A Men's Shed is "a community-based, non-profit...organization that is accessible to all men and whose primary activity is the provision of 
a safe and friendly environment where men are able to work on meaningful projects at their own pace in their own time in the company of other men" (http://mensshed.org/). There is evidence that connecting older men with a Men's Shed facilitates positive social relationships and builds resilience and a sense of belonging by providing a place for meaningful activity in the company of other men (Ormsby et al., 2010). The relevance of this type of program for older gay men specifically, however, has yet to be investigated. In the state of Victoria where this research was conducted, Vintage Men (http://www.primetimersww.com/vintagemen/) and Val's Café (http://valscafe.org.au/) provide safe spaces for older gay men to connect and socialize. Research investigating the role such organizations play in the lives of older gay men, however, has yet to be conducted.

In addition to providing older gay men opportunities to form friendships, interventions which increase the cultural competence of health professionals for working with older gay men are needed. Fredriksen-Goldsen et al. (2014) detail core competencies and strategies for working with older gay, lesbian, bisexual, and transgender (LGBT) adults. Analyzing one's own personal and professional attitudes toward sexual orientation and gender; understanding how social, legal, and cultural contexts have negatively impacted on LGBT older adults; understanding how service provider systems, policies, and resources may impact on older LGBT adults; understanding the different needs of subgroups of LGBT older adults and tailoring care accordingly; and using culturally appropriate language can all assist in providing health professionals that meet the needs of older gay men. Increasing the cultural competence of health professionals should be seen as a priority in combatting depression among older gay men.

The results and implications of this study need to be considered in the light of several limitations. The current study is unable to determine causality due to its correlational design. The outcome factor was depressive symptoms, assessed through the use of a screening tool. The results do not apply, therefore, to a diagnosed depressive disorder. A sense of belonging with gay friends was assessed via visual analogue scales, as there is no existing instrument to measure this construct. Examining the psychometric properties of the measure would be valuable. This study utilized a convenience sample of older gay men recruited via a range of strategies. Due to the recruitment methods utilized, the gay men who came into contact with this research are more likely to have some degree of existing involvement with the gay community (e.g. attending a gay event, reading a gay magazine, visiting gay websites). The current study did not assess the men's connectedness with family members. It is likely that older gay men with lower levels of connectedness with family lived alone, and this is a variable that could have been controlled for in the analyses.

Future research needs to investigate ways to increase social relationships among older gay men, and whether programs developed to meet this need are effective. The need to understand older gay men's friendships is important, and the results of this research indicate that it is particularly important for older gay men who live alone. Results imply that a sense of belonging with gay friends partly compensates for living alone. Interventions aimed at increasing sense of belonging with gay friends among older gay men who live alone are likely to have benefits for their mental health.

\section{Conflict of interest}

None.

\section{References}

Baumeister, R. F. and Leary, M. R. (1995). The need to belong: desire for interpersonal attachments as a fundamental human motivation. Psychological Bulletin, 117, 497-529. doi: 10.1037/0033-2909.117.3.497

Chou, K. L., Ho, A. H. and Chi, I. (2006). Living alone and depression in Chinese older adults. Aging and Mental Health, 10, 583-591. doi: 10.1080/13607860600641150

Cochran, S. D. and Mays, V. M. (2009). Burden of psychiatric morbidity among lesbian, gay, and bisexual individuals in the California quality of life survey. Fournal of Abnormal Psychology, 118, 647-658. doi: 10.1037/a0016501

de Vries, B. and Megathlin, D. (2009). The meaning of friendships for gay men and lesbians in the second half of life. Fournal of GLBT Family Studies, 5, 82-98. doi: 10.1080/15504280802595394

Fredriksen-Goldsen, K. I., Hoy-Ellis, C. P., Goldsen, J., Emlet, C. A. and Hooyman, N. R. (2014). Creating a vision for the future: key competencies and strategies for culturally competent practice with lesbian, gay, bisexual, and transgender (LGBT) older adults in the health and human services. Fournal of Gerontological Social Work, 57, 80-107. doi: 10.1080/01634372.2014.890690

Fredriksen-Goldsen, K. I., Kim, H.-J., Barkan, S. E., Muraco, A. and Hoy-Ellis, C. P. (2013). Health disparities among lesbian, gay, and bisexual older adults: results from a population-based study. American fournal of Public Health, 103, 1802-1809. doi: 10.2105/AJPH.2012.301110

Hagerty, B. M., Lynch-Sauer, J., Patusky, K. L., Bouwsema, M. and Collier, P. (1992). Sense of belonging: a vital mental health concept. Archives of Psychiatric Nursing, 6, 172-7. doi: 10.1016/0883-9417(92)90028-H 
Hayes, A. F. (2013). Introduction to Mediation, Moderation, and Conditional Analysis: A Regression-Based Approach. New York, NY: Guildford Press.

Hollister-Wagner, G. H., Foshee, V. A. and Jackson, C. (2001). Adolescent aggression: models of resiliency. Fournal of Applied Social Psychology, 31, 445-466. doi: 10.1111/j.1559-1816.2001.tb02050.x

Kamiya, Y., Doyle, M., Henretta, J. C. and Timonen, V. (2013). Depressive symptoms among older adults: the impact of early and later life circumstances and marital status. Aging $\mathcal{E}$ Mental Health, 17, 349-357. doi: 10.1080/13607863.2012.747078

LeBeau, R. T. and Jellison, W. A. (2009). Why get involved? exploring gay and bisexual men's experience of the gay community. Fournal of Homosexuality, 56, 56-76. doi: 10.1080/00918360802551522

Lewinsohn, P. M., Seeley, J. R., Roberts, R. E. and Allen, N. B. (1997). Center for Epidemiologic Studies Depression Scale (CES-D) as a screening instrument for depression among community-residing older adults. Psychology of Aging, 12, 277-87. doi: 10.1037/0882-7974.12.2.277

Lyons, A. (2015). Social support and the mental health of older gay men: findings from a national community-based survey. Research on Aging, Advance online publication. doi: 10.1177/0164027515588996

Lyons, A., Pitts, M. and Grierson, J. (2012). Growing old as a gay man: psychosocial well-being of a sexual minority. Research on Aging, 35, 275-295. doi: 10.1177/0164027512445055

Lyons, A., Pitts, M. and Grierson, J. (2013). Factors related to positive mental health in a stigmatized minority: an investigation of older gay men. Fournal of Aging and Health, 25, 1159-1181. doi: 10.1177/0898264313495562

McLaren, S., Gibbs, P. M. and Watts, E. (2013). The interrelations among age, sense of belonging and depressive symptoms among gay men and lesbians. Fournal of Homosexuality, 60, 1-15. doi: 10.1080/00918369.2013.735933

McLaren, S., Gomez, R., Bailey, M. and Van Der Horst, R. (2007). The association of depression and sense of belonging with suicidal ideation among older adults: applicability of resiliency models. Suicide and Life-Threatening Behavior, 37, 89-102. doi: 10.1521/suli.2007.37.1.89

McLaren, S., Jude, B. and McLachlan, A. J. (2008). Sense of belonging as a predictor of depression among Australian gay men. International Fournal of Men's Health, 7, 90-99. doi: 10.3149/jmh.0701.90

Morris, S., McLaren, S., McLachlan, A. J. and Jenkins, M. (2015). Sense of belonging to specific communities and depressive symptoms among Australian gay men. Fournal of Homosexuality, 62, 804-820. doi: 10.1080/00918369.2014.999491

Nock, M. K. et al. (2008). Cross-national prevalence and risk factors for suicidal ideation, plans and attempts. The British Fournal of Psychiatry, 192, 98-105. doi: 10.1192/bjp.bp.107.040113
Oh, D. H., Park, J. H., Lee, H. Y., Kim, S. A., Choi, B. Y. and Nam, J. H. (2015). Association between living arrangements and depressive symptoms among older women and men in South Korea. Social Psychiatry and Psychiatric Epidemiology, 50, 133-141. doi: 10.1007/s00127-014-0904-2

Ormsby, J., Stanley, M. and Jaworski, K. (2010). Older men's participation in community-based men's sheds programmes. Health and Social Care, 18, 607-613. doi:10.1111/j.1365-2524.2010.00932.x

Pirkis, J. et al. (2009). The community prevalence of depression in older Australians. Fournal of Affective Disorders, 115, 54-61. doi: 10.1016/j.jad.2008.08.014

Plöderl, M., Sellmeier, M., Fartacek, C., Pichler, E-M., Fartacek, R. and Kralovec, K. (2014). Explaining the suicide risk of sexual minority individuals by contrasting the minority stress model with suicide models. Archives of Sexual Behavior, 43, 1559-1570. doi: 10.1007/s10508-014-0268-4

Polku, H. et al. (2015). Life-space mobility and dimensions of depressive symptoms among community-dwelling older adults. Aging $\mathcal{E}$ Mental Health, 19, 781-789. doi: 10.1080/13607863.2014.977768

Purcell, B., Heisel, M. J., Speice, J., Franus, N., Conwell, Y. and Duberstein, P. R. (2012). Family connectedness moderates the association between living alone and suicide ideation in a clinical sample of adults 50 years and older. American fournal of Geriatric Psychiatry, 20, 717-723. doi: 10.1097/JGP.0b013e31822ccd79

Radloff, L. S. (1977). A self-report depression scale for research in the general population. Applied Psychological Measurement, 1, 385-401. doi: 10.1177/014662167700100306

Shippy, R. A., Cantor, M. H. and Brennan, M. (2004). Social networks of aging gay men. The fournal of Men's Studies, 13, 107-120. doi: 10.3149/jms.1301.107

Stonewall. (2011). Lesbian, gay and bisexual people in later life. Retrieved from: http://www.stonewall.org.uk/sites/ default/files/LGB_people_in_Later_Life_2011_.pdf

Tintle, N., Bacon, B., Kostyuchenko, S., Gutovich, Z. and Bromet, E. J. (2011). Depression and its correlates in older adults in Ukraine. International fournal of Geriatric Psychiatry, 26, 1292-1299. doi: 10.1002/gps.2681

Van Orden, K. A., Witte, T. K., Cukrowicz, K. C., Braithwaite, S. R., Selby, E. A. and Joiner, T.E. (2010). The interpersonal theory of suicide. Psychological Review, 117, 575-600. doi: 10.1037/a0018697

Wight, R. G., LeBlanc, A. J., de Vries, B. and Detels, R. (2012). Stress and mental health among midlife and older gay-identified men. American Fournal of Public Health, 102, 503-10. doi: 10.2105/AJPH.2011.300384.

Woolwine, D. (2000). Community in gay male experience and moral discourse. Fournal of Homosexuality, 38, 5-37. doi: 10.1300/J082v38n04_02

Zhang, L., Xu, Y., Nie, H., Zhang, Y. and Wu, Y. (2012). The prevalence of depressive symptoms among the older in China: a meta analysis. International fournal of Geriatric Psychiatry, 27, 900-906. doi: 10.1002/gps.2821 